\title{
Report from the PC user group
}

\author{
MARGARET D. ANDERSON \\ State University of New York, College at Plattsburgh, Plattsburgh, New York
}

The group met to discuss issues related to the use of PCs for research and instruction. Some of the topics covered have been items of concern for the users groups for the past 2 years, while others were new topics for discussion this year. The questions raised and issues discussed are summarized below with the addition of several references so that readers may pursue items that are of special interest to them.

\section{Transportability of Data}

There was significant interest in the issue of the possibility of transporting data between PCs and Macs. At this time, it appears that there is no program that will directly convert files from one system to the other. However, data stored in ASCII can usually be used by both systems, but those wishing to do so should check on their specific software parameters.

\section{Object-Oriented Programming}

A discussion followed concerning the fact that objectoriented programming may be able to facilitate transportability of data and programs between machines with different operating systems. For more on this topic, see Dixon (1991) and Lesgold et al. (1991) in this issue.

\section{Scanners}

A question was raised concerning the availability and evaluation of scanners. The Calera by True Scan was highly recommended. It appears to be reasonably priced, produces a high-quality product, and is able to deal efficiently with proportional spacing. ScanMan Plus, manufactured by LOGITECH, was recommended as being an inexpensive hand-held scanner which can deal particularly well with line drawings or images where no sensitive gray scale is required. Some information concerning scanners has been published in PC Magazine (January 26, 1988, p. 43 , and September 27,1988, p. 28) also in Byte (December 1987 , p. 165).

\section{Viruses}

As in the past, there was considerable interest in the topic of viruses. The general consensus was that individuals need to be very cautious about any software they

The author's mailing address is Department of Psychology, State University of New York, Plattsburgh, NY 12901. acquire, regardless of its source. Any new software should be subjected to a thorough virus search before being used. Antivirus vaccines were recommended and are usually available on all campuses. Users should be careful to get the most recent vaccine available as new viruses are constantly being developed and outdated vaccines will not catch them. For a complete review and discussion about viruses, see Schneider (1989).

\section{Legal Issues}

The discussion about viruses led to a discussion concerning the legal issues relating to individuals who create viruses as an expression of their creativity. This was followed with questions relating to the legal rights of software developers and the ability to patent programs. While not much is yet known about it, it appears that this is an area of great interest and is in an early stage of growth. Brian Kahin, at Harvard University, is a lawyer who specializes in legal issues relating to electronic media.

\section{Test Generation}

Once again, the question relating to the use of standardized test banks versus the generation of personalized tests using test generators or word processors was raised. For a review of the current state of item bank software versus word processing, see Gullickson and Farland (1990). Sturtevant and Johnson (1988) provide a good review of software for microcomputer test generating, and Bradley (1990) gives advice on how to use a word processor to generate tests.

\section{Future Users Groups}

The suggestion was made that, in the future, user group meetings should not be divided on the basis of hardware. Many individuals use two or more hardware systems, and the systems being used are in a transition stage. Although PCs and Macs seem to enjoy the greatest popularity, there are still some campuses where Apples are being used and there are some campuses that are moving toward either Unix-based machines or NeXt computers. It was felt that it would be advantageous to have users of all machines at a single discussion session so that they could answer questions related to their specific machines, convertibility of data and programs, and so forth. If the discussion groups are to be split in the future, it was suggested that they be divided along the lines of uses (e.g., instruction, research) rather than hardware. 


\section{Parting Shot}

The final question raised was "What's available on CDRom for psychology?"

\section{REFERENCES}

Bradley, D. R. (1990). IBM PC, PS/2, and compatibles. Behavior Research Methods, Instruments, \& Computers, 22, 266-267.

Dixon, P. (1991). The promise of object-oriented programming. Behavior Research Methods, Instruments, \& Computers, 23, 134-141.
Gullickson, A., \& Farland, D. (1990). Using micros for test development, item bank software versus word processing. Tech Trends, $35,22-26$.

Lesgold, A.. Hughes, E., Bunzo, M., McGinnis, T ., Gordin, M., RAo, G., \& Prabowo, R. (1991, November). Tools for developing interactive software for research and education. Paper presented at the annual meeting of the Society for Computers in Psychology, New Orleans.

SCHNEIDER, W. (1989). Tutorial: Computer viruses. Behavior Research Methods, Instruments, \& Computers, 21, 334-340.

StuRTEVANT, V., \& Johnson, B. (1988). Micro-computer test-generation systems: A software review. Teaching Sociology, 16, 49-54. 